\title{
Prudente de Moraes, neto e a política cultural do Estado Novo
}

Leonardo D’Avila

$\mathrm{UFSC} / \mathrm{CNPq}^{1}$

\begin{abstract}
Resumo
O artigo procura evidenciar alguns desdobramentos da obra de Prudente de Moraes, neto ${ }^{2}$ e de seu pseudônimo Pedro Dantas em relação às políticas culturais do Estado Novo (1937-1945). Nesse sentido, sua ensaística de nacionalidade, a exemplo dos textos publicados na revista Cultura Política, ao mesmo tempo em que busca afirmar a formação da nacionalidade do Brasil, também pode ter suas próprias descontinuidades evidenciadas em metáforas, como a de se jogar as "cartas na mesa". Ao aproximar esses ensaios com a poesia do autor, esta leitura ressalta uma politicidade em seus textos, especialmente pela retomada paródica da tradição e pela reflexividade de suas metáforas. Nesses gestos, os tropos da poesia e da ensaística de Prudente puderam inoperar a fabricação de uma nacionalidade institucionalizada e resistir às intempéries das políticas culturais estatais.
\end{abstract}

Palavras-chave: Prudente de Moraes, neto; Políticas culturais; A Cachorra; Estética; Ética.

\begin{abstract}
This article aims to demonstrate some outcomes of the works of Prudente de Moraes, neto and his pseudonym Pedro Dantas related to the cultural policies of the Brazilian Estado Novo (1937-1945). In this sense, his essays of nationality, as well as his texts published in the Cultura Politica review, at the same time that seek to affirm the Brazilian cultural formation, can also have its discontinuities evidenced in metaphors, as the one of throwing the "cards on the table". When approaching these essays with the author's poetry, this lecture emphasize a politicity in his texts, specially by the parodic recapture of the tradition and by the reflexion of its metaphors. In these gestures, the tropes of the poetry and the essays of Prudente could make inoperative the intitucionalized nationality and resist to the volatilities of the State's cultural policies.
\end{abstract}

Keywords: Prudente de Moraes, neto; Cultural Policies; A Cachorra; Aesthetics; Ethics.
1. Este artigo é parte de projeto de pesquisa financiado pelo Conselho Nacional de Desenvolvimento Científico e Tecnológico, CNPQ.

\section{Manteve-se a escrita do} nome do autor conforme era difundida, separado por uma vírgula e com a palavra neto em letras minúsculas. 


\section{Literatura de Ideias: formação nacional e cartas na mesa}

3. DANTAS, Pedro. "Literatura de ideias I". Cultura Política, 1941, p. 258.

4. Ibidem, p. 259.
A revista Cultura Politica, publicação do Departamento de Imprensa e Propaganda (DIP) do Estado Novo, já em seu primeiro número, de março de 1941, apresentou a coluna "Literatura de Ideias" assinada por Pedro Dantas, pseudônimo de Prudente de Moraes, neto. Ela consistiu em um conjunto de ensaios publicados em dez números (de março a dezembro de 1941), os quais tratavam sobre textos de variados autores que teriam assumido a tarefa de pensar o Brasil. Discutir ideias, naquele momento, era necessariamente discutir o Brasil, país que, para Dantas, tomava posse de si mesmo nas últimas décadas. Assim, "em todos os domínios, sob todas as formas, o Brasil é o grande assunto do espírito brasileiro, a sua última e absorvente descoberta"3. O colunista propunha ser a hora da política e das artes observarem as características espontâneas do país, tanto as mais aceitáveis quanto as mais discutíveis, sem preconceitos e, sobretudo, sem um referencial político abstrato ou algum esforço de importação cultural. Em outros termos, Dantas pensava que os brasileiros passavam a ser sinceros sobre o próprio Brasil, o que poderia ser o primeiro passo para compreenderem sua formação, algo que vem descrito em uma nova alegoria, no caso, a das cartas na mesa.

(...) chegou também a hora do Brasil. Quer dizer, o momento de começarmos a nos apresentar com toda a naturalidade, sem cenografia e sem disfarces, que nunca se sabe quando são hábeis. Simplesmente as cartas na mesa, pois a nossa experiência recente aí está, a indicar que, no jogo dos valores de cultura, ninguém pode saber de antemão a que perde e a que ganha. As cartas na mesa, com o que tivermos: não nos suceda, por pretensa sabedoria, ocultar a que nos pareça desvaliosa ou comprometedora, para descobrir mais tarde que estávamos malbaratando um dos melhores trunfos. ${ }^{4}$

Essa espontaneidade argumentada pela ensaística de Pedro Dantas dependeria de uma sinceridade da parte do intelectual para se abrir aos verdadeiros passos da formação nacional, independentemente de juízos de valor, sendo, por exemplo, o caso de se transpor boa parte das conquistas do modernismo, do qual Prudente participara, para uma redefinição do pensamento brasileiro. Para seu pseudônimo Pedro Dantas, nesse texto, o processo que pode culminar em uma literatura de ideias acerca do "espírito nacional" se deu lenta e continuamente. Desse modo, 
insolúvel problema filosófico da aplicação de um critério de continuidade ao que é contínuo. O que, desde Zenão de Eléa, só tem servido para acrescentar justo motivo de perplexidade ao pensamento humano, já tão assoberbado de obscuridades e mistérios. ${ }^{5}$

Pedro Dantas preferiu não se utilizar de termos que definissem os limites claros para alguma identidade nacional, preferindo, antes, a palavra espírito, muito mais problemática, pois poderia conotar um significado tendente ao religioso bem como sugerir algum tom vitalista, o qual é reforçado pela menção a Zenão de Eleia, o mais célebre dos pensadores estoicos antigos e um dos primeiros a conceituar espírito. Se não procurava um critério de continuidade, buscava, em contrapartida, considerar as descontinuidades em um âmbito mais amplo. Dessa maneira, o espírito nacional consistiria em um jogo de forças, uma energia vital e um lugar precário dentro de um conjunto de diferenças, mais do que uma essência imutável ou uma instituição outorgada. Resumidamente, o autor ensaia uma identidade não mais com integridade ontológica estável, mas que, por outro lado, não deixa de manifestar um certo evolucionismo, especialmente se esse espírito fosse observado em sentido retrospectivo.

A revista Cultura Política, que manteve periodicidade entre 1941 e 1945, foi dirigida por Almir de Andrade, que por sua vez, respondia ao próprio Departamento de Imprensa e Propaganda (DIP), comandado por Lourival Fontes. O periódico mantinha em seus artigos e colunas um ecletismo de temas para pensar a cultura brasileira, além de uma pluralidade de escritores de diferentes ideologias, agrupando personalidades de esquerda, como Graciliano Ramos ou Nelson Werneck Sodré ao lado de ex-integralistas, como Guerreiro Ramos ou o próprio diretor Lourival Fontes. Mas, apesar do pluralismo entre os contribuintes, a revista era uma iniciativa direta da política cultural do Estado Novo em busca por uma brasilidade e, mais do que isso, na formação de um público leitor fundado a partir desse propósito.

A coluna "Literatura de Ideias," dentro dessa iniciativa, foi um feixe para as variadas discussões havidas no período de docência de Prudente de Moraes, neto na Universidade do Distrito Federal na qual dialogou com os trabalhos de outros intelectuais, como Manuel Bandeira, Mário de Andrade, Afrânio Peixoto, Heitor Villa-Lobos, Gilberto Freyre, entre outros. Embora sejam escassas as fontes sobre essas aulas de Prudente, suas investigações sobre literatura a partir de uma nacionalidade espontânea foram parcialmente registradas em um desconhecido ensaio sobre o romance brasileiro, que havia sido encomendado pelo Ministério das Relações Exteriores. O texto partia justamente do pressuposto de estabelecer um olhar sincero sobre a
5. Ibidem, p. 258. 
6. Apostila publicada pelo Ministério das Relações

Exteriores, resumo n. 3, 1939.

7. Há uma enorme proximidade entre a busca por origens formadoras da literatura brasileira realizadas por Prudente e Candido, devendo-se apenas destacar que, enquanto no primeiro prevalece o tom idealista e a vontade de síntese, Candido dá maior prevalência às contradições, isto é, aos momentos decisivos.

8. CANDIDO, Antonio. Formação da Literatura Brasileira, 1959, p. 402.

9. Cf. FÁVERO, Maria de Lourdes. "Anísio Teixeira e a Universidade do Distrito Federal". Revista Brasileira de História da Educação, 2008, p. 177. cultura brasileira de maneira a destacar as mais distintas particularidades tais como fossem, o que era diferente de sustentar um ufanismo à maneira integralista. Assim, à mesma época em que seu grande amigo Sergio Buarque de Holanda publicou Raizes do Brasil, Prudente, em um gesto que não nega certo hegelianismo, passou a destacar o valor das próprias contradições para a formação de uma literatura brasileira. "Nessa pesquisa inútil mas inevitável, inevitável porque está na natureza humana, inútil porque a ordem natural não se apressa e a solução procurada virá por si mesma, e a seu tempo, os romancistas vão colabo-

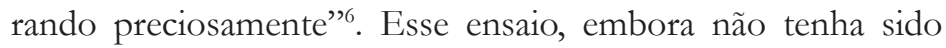
muito difundido, foi muito impactante para Antonio Candido ${ }^{7}$ posteriormente, que em uma nota marginal de sua obra mais conhecida admite:

Não há estudo crítico fundamentado e amplo sobre o nosso romance romântico, muito menos sobre as suas origens. O trabalho de Prudente de Moraes, neto, O Romance Brasileiro, Min. Das Rel. Exteriores, Divisão de Cooperação Intelectual, Resumo no 3, Rio, 1939, (mimeografado), sendo um ensaio sobre todas as suas épocas, é todavia o que melhor apresenta as condições do seu aparecimento, em pouco mais de três páginas admiravelmente densas e ricas de sugestão, nas quais me inspirei para algumas linhas da interpretação proposta. Fica entendido que daqui por diante está implícita a referência a este ensaio, para todos os romancistas estudados. ${ }^{8}$

As contribuições de Prudente de Moraes, neto na revista Cultura Política acusam o velamento de uma tensão ocorrida entre a elaboração de um projeto de nação no Estado Novo pela política cultural oficial e alguns ataques à intelectualidade, como na grande decepção gerada pelo fim precoce da Universidade do Distrito Federal. O projeto arrojado do educador Anísio Teixeira para a instituição municipal foi, ao longo de cinco anos, completamente desmantelado. Portanto, a tarefa de Prudente enquanto professor de Literatura e também diretor da Faculdade de Letras mostrou-se muito delicada, tendo em vista que assumiu seu posto logo após a exoneração e até mesmo a prisão de seus principais fundadores, como os diretores Edgardo Castro Rebello, Hermes Lima, Leônidas Rezende, Luiz Carpentier, o reitor Afrânio Peixoto e o próprio idealizador Anísio Teixeira. Além da questão ideológica, o fato da Universidade do Distrito Federal ser uma instituição de ensino superior municipal criava um problema jurídico quando a nova política educacional imposta por Capanema não reconhecia a possibilidade de serem geridas por municípios? ${ }^{9}$ Embora o imbróglio legal da UDF sugira não ter havido um golpe da parte do Ministério da Educação e Saúde Pública, a partir de uma observação do 
contexto, nota-se que seu fim não foi jurídico, mas eminentemente político. Isso porque em 1938, o próprio ministro Gustavo Capanema indicou deliberadamente Alceu Amoroso Lima para a reitoria, provocando grande crise na instituição, dado que o líder católico havia sido um dos maiores opositores ao projeto educacional arrojado e democrático elaborado por Teixeira. Por fim, a Universidade do Distrito Federal foi extinta pelo decreto-lei n. 1.063, de 20 de janeiro de 1939. Após o incidente e outras mudanças administrativas, José Baeta Viana, o último reitor da UDF, por ocasião de sua exoneração em 1939, enviou palavras de amizade a Prudente: "Felizmente, nem tudo é perdido. De toda essa catástrofe que desabou sobre nossas cabeças ficou-me um apunhado de amizades entre as quais eu tenho a grata satisfação de contar a sua pessoa"10. Essa alegórica catástrofe sobre a cabeça, que foi a sua incorporação à Universidade do Brasil, atual UFRJ, fez da UDF um grande motivo de decepção para uma série de artistas e intelectuais daquele momento. Prudente foi um deles, que deixa transparecer certa mágoa em suas palavras sobre o Ministro da Educação e Saúde Gustavo Capanema, como alguém "que acabou com a minha universidade, mas gosta muito de mim e eu dele" ${ }^{11}$.

É um tanto quanto suspeita a lisonja da ensaística de Dantas em conclamar a sinceridade, isto é, as cartas na mesa, por parte dos intelectuais como solução para o reconhecimento da verdadeira formação cultural do Brasil, como salientou em Cultura Política, dois anos após Capanema haver "acabado" com a sua universidade. Mas, para além desse sentido de sinceridade como transparência, muito próximo ao senso comum, a metáfora das cartas na mesa pode ser lida de modo mais detalhado, especialmente a partir de alguns momentos niilistas de outros periodos de sua ensaística. Um possível embaralhamento aparece no quinto ensaio da coluna "Literatura de Ideias", quando Pedro Dantas conceitua um "espaço de vazio", que separaria Gilberto Freyre de Oswald de Andrade, mas que seria a possibilidade de aproximar dissímiles, rompendo com opções binárias. Nesse sentido, reconhece que Freyre ficou deslocado das discussões modernistas por sua posição mais conservadora e por seu período fora do país, mas que, por outro lado, lidou com uma série de autores que não foram tratados pelos modernistas, sendo indiscutível sua contribuição para as ideias nacionais. Afirma o autor que um "nada" os uniria:

Entre o escritor paulista e o nordestino há, evidentemente, muito mais pontos de divergência do que de contato. Se um nada os une, quase tudo os separa. Mas esse nada é, para um e para outro, de tal modo importante e significativo que não devemos admirar-mos sobremaneira de encontrar, por vezes, na poesia e no romance de João Miramar, alguma
10. Carta de José Baeta Vianna a Prudente de Moraes, neto, de 25 de janeiro de 1939, constante no arquivo do Instituto Histórico e Geográfico Brasileiro, lata 590, pasta 50.

11. Moraes, neto, apud. BARBOSA, Ana Claudia. Perfil de Prudente de Moraes, neto, 2002, p.83. 
12. Em Maitres et Esclaves, de 1953, Barthes compara Freyre a Marc Bloch e Fernand Braudel. BARTHES, Roland. Inéditos v. 4, 2005, p. 40-43.

13. A relação entre table e tableau foi pensada por Georges Didi-Huberman no catálogo de sua exposição Atlas: como levar o mundo nas costas, realizada no museu Reina Sofía em Madrid entre 2010 e 2011, e destacou, a partir do ponto de um ponto de partida inspirado em Aby Warburg, as potencialidades de um trabalho horizontal com as imagens.

14. José Olympio enviou uma carta a Prudente em 7 de abril de 1976, com a intenção de persuadi-lo a publicar sua obra literária. "Prudentinho, converse com sua mulher. Peça a ela, em meu nome, que exija do escritor Pedro Dantas que não continue privando a mocidade universitária brasileira, e a todo o Brasil intelectual, de conhecerem sua obra literária. Aqui fica meu apelo. Meu e nosso, da Casa". Carta datada de 7 de abril de 1976 a Prudente de Moraes, neto conservada no arquivo da Casa Rui Barbosa, Caixa 1.

15. A única publicação que conseguiu reunir uma parte considerável da obra foi a tese de Augusto Massi: MASSI, Augusto. Militante Bissexto, 2004. coisa que aparece sob a forma de ideia no sociólogo de "Casa Grande", enquanto, por seu turno, a Gilberto Freyre já tem sucedido revelar-se um poeta da Antropofagia ou do Pau-Brasil.

Dantas não fala de uma negatividade que separa Freyre de Oswald, senão de um nada. Um nada que, ainda assim, é fator de aproximação de textualidades, algo que seria próprio da Antropofagia de Oswald, mas não menos da Casa Grande e Senzala, livro cuja exaustividade interessaria profundamente Roland Barthes alguns anos mais $\operatorname{tarde}^{12}$. E esse nada romperia com separações como nativo / estrangeiro, modernismo paulista / modernismo nordestino para justamente abrir um espaço (topos) vazio: um saber efêmero capaz de abarcar relações mais paradoxais da formação nacional. As cartas na mesa foram sinônimo de transparência na coluna "Literatura de Ideias". Contudo, se a metáfora das cartas for retomada em função desse nada, ela pode ser também uma abertura à contingência e à aproximação dissímiles, analogamente ao que propôs recentemente Didi-Huberman ao lidar horizontalmente com as imagens como se fosse uma mesa de operações (table) em vez de um quadro (tableau $)^{13}$. No mais, esse mesmo nada pode levar ao questionamento do grande descompasso entre a ensaística de nacionalidade de Dantas, profundamente especulativa e evolutiva, com sua poesia, muito marcada por violência, paródia e anacronia.

\section{A Cachorra e seu complemento: a dor de Menelau}

Prudente de Moraes, neto publicou alguns contos esparsos na década de vinte, como "Os mortais de Nero", publicado no primeiro número da revista Estética, de março de 1924, revista que fundou com Sergio Buarque de Holanda. A publicação procurou ser uma sucessora de Klaxon e serviu de palco para querelas importantes do modernismo, assim como abriu espaço para as primeiras discussões sobre o surrealismo no Brasil. Contudo, praticamente deixa de escrever contos na década de $30 \mathrm{e}$, em contrapartida, volta-se principalmente para a poesia nesse momento, quase sempre assinando os poemas como Pedro Dantas.

Prudente nunca chegou a publicar um livro com seus textos poéticos ou seus contos, a despeito da insistência de amigos e editores, como José Olympio, que insistiu até $1976^{14}$. Sua obra circulou principalmente em correspondências ou em publicações periódicas, como jornais ${ }^{15}$. De qualquer modo, ela foi muito admirada, inclusive por nomes como Vinícius de Moraes, 
Mário de Andrade ou Manuel Bandeira, apesar de ter sido reconhecida como uma poesia um tanto quanto errática e eventual. Por isso Prudente, ou melhor, Pedro Dantas recebeu a alcunha de poeta bissexto: que, portanto, era um poeta de grande valor, apesar de não ter uma escrita costumaz, conforme Manuel Bandeira repetidas vezes o enquadrou em jornais e antologias ${ }^{16}$.

O poema mais reconhecido de Pedro Dantas foi "A Cachorra", que passou a circular a partir de 1938 em correspondências, portanto contemporaneamente às experiências frustradas da UDF. Foi publicado posteriormente no suplemento "Autores e Livros", do jornal $A$ Manhã, de 3 de setembro de 1944. Composto em redondilha maior e com rimas pobres, perfaz um dilaceramento a partir de uma agressão repetitiva por uma criatura metamórfica, vindo a terminar em uma epifania e quebra do ritmo. O poema inicia com a figuração de uma agressão incessante sobre um corpo inerte. A agressão continua no mesmo ritmo e nas mesmas pancadas (ou, ou, ou...) ao longo do poema, cujos despedaçamentos incessantes são desferidos por uma manifestação metamórfica que nunca se revela, a não ser por figurações rápidas de garras, dentes, tentáculos e patas de alguma fera. Aquele que sofre é apenas identificado como "amante", sendo que o eu-lírico praticamente não reage aos golpes e tampouco se consuma na morte, como se fosse um Prometeu ofegante sem qualquer dom para oferecer.

\section{A Cachorra}

Veio uma angústia de cima

Pelos ombros me agarrou

No mais fundo do meu peito

Sua lâmina cravou

Depois que no chão desfeito

O meu corpo estrebuchou

Pelos cabelos a fera

Sobre as pedras me arrastou.

Meu corpo se espedaçou.

Mas ainda não satisfeita

Nova vida me insuflou:

Para mostrar poderio

Com a sua mão direita

Uma cidade arrasou

$\mathrm{Na}$ esquerda tomou um rio

Fogo nas águas soprou

As águas todas do rio

Com seu hálito secou

Levou-me aos cimos mais altos

No ar me imobilizou

Depois em súbitos saltos

A garra adunca fincando

No meu coração, lá do alto

Meu corpo logo afundou.
16. Entre elas: Antologia de poetas brasileiros bissextos contemporâneos. Manuel Bandeira (Org.), 1946. 
17. DANTAS, Pedro. "A

Cachorra". In: Antologia dos poetas brasileiros bissextos, 1946, p. 167-168.

18. Ibidem, p. 167-168.
19. DANTAS, Pedro. Cantiga de Mestria. Letras e Artes, 1947, p. 8.
Veio buscar-me de novo:

Angina-pectoris, polvo,

Meu coração sufocou

E tais surras de chicote

Me deu, que a cada lambada

Minh'alma mortificada

Minh'alma perto da morte

Só a morte desejou;

Meu rosto esfregou na lama

As faces me babujou

E quando, à atroz azafama,

O meu olhar se turvou

Vencido entregue arquejante

- Perdido o sangue das veias -

$\mathrm{Na}$ praia sobre as areias

Meu corpo exausto rodou.

Ah! Pobre corpo do amante

Que até o fim se humilhou!

Então um riso infamante

As fauces lhe escancarou

Zombou da minha tolice

"Eu sou a Cachorra", disse,

"Tu me chamaste: aqui estou".

A essa voz dissiparam-se as sombras

E enquanto ela me mastigava os últimos restos da memória Senti que da sua boca nasciam rosas

E vi que o céu se rasgava para maravilhosa aparição. ${ }^{17}$

Assim que o eu-lírico é nomeado simplesmente como "amante", a criatura passa a se apresentar "'Eu sou a Cachorra', disse, / Tu me chamaste: aqui estou"18. Essa individuação é seguida por uma quebra na métrica de heptassílabos para dar lugar a versos livres. No mais, nessa última estrofe a desfiguração do amante e os verbos que conotam violência permanecem, exceto que, desta vez, há lugar para alguma forma de epifania, quando o amante tem no verbo ver sua primeira e única ação; nesse instante, o dilaceramento já não se dá apenas no corpo, mas no próprio céu, o que é sentido como "maravilhosa aparição".

O texto é interessante por retomar temas e termos das cantigas de amor, especialmente o da coita, o que fica até mais claro em outros poemas seus da mesma época cujos títulos são cantigas, como "Cantiga do fim do mundo" ou "Cantiga de mestria". Esse último poema, por exemplo, explicita a temática da coita e até certa emulação da poesia trovadoresca em sua última estrofe: "Só deste amor não tolero / mais penas quais já sofri. / A alma dilacerada / de tão grã coita, antes quero / aos pés da mulher amada / praticar o harakiri""19. O poema "Cantiga de mestria", assim como "A Cachorra", perfaz uma desilusão amorosa pelo retorno da tradição, antes de um lirismo pessoal relativo ao autor. Nesse proceder, o eu-lírico dilacerado pela coita 
almeja a morte, a qual é vislumbrada por certo estranhamento, quando se manifesta o suicídio ritual japonês, cujo significante, haraquiri, já impõe certo corte à familiaridade que vinha sendo construída com a poesia trovadoresca.

Ao final de "A Cachorra", também ocorre um corte: as redondilhas são substituídas subitamente por versos livres, momento em que a violência continua, exceto que com ares de epifania: "E vi que o céu se rasgava para maravilhosa aparição"20. No mais, o poema justapõe temas eternos da dor de amante em face de uma criatura que dilacera seu corpo. Criatura tão infame quanto a aceleração temporal da modernidade, que, Benjamin à mesma época, afirmava tudo modificar, exceto o céu ${ }^{21}$. Velocidade que, portanto, se dá pela aceleração das imagens no poema, que não se traduziria em um ganho de experiência, mas de pobreza, inação e violência para o corpo humano abandonado.

Após todas essas figurações de agressão por um ser metamórfico, finalmente surge uma corporificação. "Eu sou a Cachorra", disse, / "Tu me chamaste: aqui estou." A identificação do monstro se dá na nomeação da "Cachorra", que escancara tanto uma monstruosidade como um termo pejorativo, inclusive com o emprego do "c" maiúsculo, condensando, portanto, as figurações de agressão em um nome próprio. Dessa confluência, segue um aprendizado do eu-lírico, quando a aproximação de imagens perfaz uma monstruosidade, que se mostra, mas parece alterar a lei da vida. Para Deleuze e Guattari, um devir-animal não consiste em um ser íntegro e ontologicamente estável. Ao contrário, "trata-se de fazer corpo com o animal, um corpo semórgãos definido por zonas de intensidade ou de vizinhança"22. A bestialidade da "Cachorra", nesse sentido, se dá em um processo de deslocamento de referência, quando torturador e torturado não mais se distinguem e tanto quanto homem e animal são separados por um nada que concomitantemente os justapõe.

\section{A Cachorra e seu complemento: a dor de Menelau}

Embora haja uma forte semelhança e um intertexto com a tradição trovadoresca galego-portuguesa, nenhum poema de Pedro Dantas foi mais difundido do que "A Cachorra", vindo a ser considerado um clássico da poesia brasileira por poetas como Manuel Bandeira, que era chamado de "tio" por Prudente, ou mesmo Vinícius de Moraes, tratado como "primo". As primeiras leituras de "A Cachorra", estabelecidas praticamente pelo círculo de amizade de Prudente, dão grande ênfase
20. DANTAS, Pedro. "A cachorra", 1946, p. 168.

21. BENJAMIN, Walter. "Experiência e pobreza", 1994, p. 114-119.

22. DELEZE, Gilles; GUATTARI, Felix. Mil Platôs, v. 4,2000 , p. 65 . 
23. Moraes, neto, apud. MORAES, Marcos Antonio de. "Sobre a dor de Menelau". Manuscrítica, 2012, p. 139
24. Carta disponível no Instituto Histórico e Geográfico Brasileiro. Lata 590, pasta 42.

25. "Tales son un Pedro Dantas, cuyo poema "A cachorra" pasó a ser una obra maestra de la literatura brasileña. Lo mismo puede ser dicho del "O Defunto", de Pedro Nava, una de las más bellas y siniestras piezas de nuestra poesía”.

26. BANDEIRA, Manuel. "Poetas Bissextos". A Manhã, 1994, p. 117-125. O presente texto foi a base para a apresentação da Antologia dos poetas brasileiros bissextos, também organizada por Bandeira. a uma dor de Menelau. Em carta de 9 de março de 1941, responde a Mário de Andrade em tom jocoso: "Então riste de minha dor-de-corno? Tu te riste? Meu filho não és! És é um grandiosíssimo sacana, mas deixa a bichinha te pegar, que vais ver uma coisa"23. Outra menção ao poema relacionada a uma "dor de Menelau" vem expressa na carta de Vinícius de Moraes enviada de Oxford, quando questiona seu "primo" pelo não envio de "A Cachorra". O que sobressai na carta, não obstante, é um comentário sobre a dor de Menelau perante as inquietudes do "primo", que é feito, por sua vez, em um tom de profunda melancolia:

Enfim, primo, pior que frio é dor-de-corno. A sublime, primo, que come do meu prato diariamente aqui nessa solidão. Solidão povoada de poetas ingleses, que são reis da dor de corno, aquela especialmente lúcida e enxuta, sem literatura. A dor de corno de Shakespeare, por exemplo, que eu nunca tinha suspeitado. Os melôs da Dark Lady, primo são coisas (ilegível). A gente se habitua a ver o mestre assim como um gigante sem figura, uma espécie de montanha parindo poesia, mas não é não primo. A filha-da-puta deu neles também. ${ }^{24}$

Vinícius trata da Dark Lady, da dor de Menelau ou simplesmente dor-de-corno, ligada por hífens para dar entidade a tal afeto, como uma criatura gigante ou como uma grandiosidade - como a da montanha - equiparável a uma poética, mecanismo para "parir" poesia. Seria Vinícius de Morais quem iria cunhar essa força poética das desilusões amorosas como uma característica própria dos autores bissextos, primeiramente na revista Sur em setembro de $1942^{25}$. A mesma vinculação entre "A Cachorra", "dor de Menelau" e poetas bissextos acompanha a própria publicação do poema no suplemento do jornal A Manhã, em 3 de setembro de 1944. Nas palavras de Manuel Bandeira, "bissexto é um Pedro Dantas, cujo poema 'A Cachorra' passou a ser uma obra prima da literatura brasileira"26. Ou seja, tanto a menção a "A Cachorra" em Buenos Aires quanto sua primeira publicação na imprensa brasileira fizeram questão de dispor o poema lado a lado com uma especulação sobre a decepção e a "dor de Menelau" como sua maior força poética.

Essa dor de Menelau também foi a base para a criação da Antologia dos poetas brasileiros bissextos, organizada por Manuel Bandeira, a qual elenca Pedro Dantas entre outros autores de produção poética efêmera, como Affonso Arinos de Melo Franco Sobrinho, Pedro Nava, entre outros. Em sua introdução, que parte da leitura de Vinícius, Bandeira afirma a espontaneidade dos versos dos bissextos por certo sentimentalismo: "O bissexto quando se embeiça por uma mulher que não pode ser dele, faz verso na certa. Ou quando é um lusco-fusco na 
Praça Mauá e ele espera na fila o ônibus do Grajaú" ${ }^{27}$. Essa opinião, que, de certa forma, dá continuidade àquela de Vinícius, é introjetada pelo próprio Prudente, que é descrito como o bissexto por excelência. Na mesma introdução de Bandeira, Pedro Dantas é citado no que diz respeito à sua opinião sobre o fato de ser bissexto, ao que responde: “O bissexto não transforma, não elabora nada. Nos temas da vida besta e da dor de Menelau, a matéria lírica já se apresenta elaborada e pronta. O bissexto não faz mais que captá-la"28. Portanto, em uma das poucas oportunidades em que o leitor brasileiro conheceu uma fração da poesia de Pedro Dantas, prevaleceu a noção de poeta bissexto, que, se deu popularidade a poetas que não tinham regularidade de escrita, restringiu outras possibilidades de leitura. Ao considerar que para o bissexto, a matéria lírica estaria imediatamente associada ao sentimentalismo, inclusive sugerindo uma leitura pela biografia do autor, elementos propriamente poéticos de textos como "A Cachorra" não foram destacados suficientemente.

Marcos Antonio de Moraes, em um importante esforço de crítica genética publicado em 2012, leu o poema "A Cachorra" fora do biografismo e destacou o intertexto com a tradição poética portuguesa, especialmente pela presença da redondilha maior e dos temas da coita, muito comuns em cantigas trovadorescas. Segundo Moraes, em Pedro Dantas, a aproximação da cantiga com a violência restabelece a nostalgia das dores de amor acompanhada da impossibilidade de identificação clara de um “eu”. 'Em 'A Cachorra', os códigos primeiros da 'coita' esfacelam-se, para que a linguagem poética, sob o signo da hipérbole, atinja paroxismo da dor. [...] O exagero mede o sofrimento do 'amante', fecha o círculo da impossibilidade e da sujeição" 29 . $\mathrm{O}$ autor também demonstrou que o poema remete à linguagem bíblica, mais exatamente àquela do Apocalipse, farta de figurações de bestialidades e do aparecimento de prodígios. Por fim, em relação à estrofe final do poema, justamente aquela que não foi expressa em redondilha maior, Moraes entende sua epifania como um possível conhecimento advindo da "dor de Menelau". "O insight final é o ato reflexivo do eu-lírico capaz de perceber a possibilidade de a arte materializar a intuição poética por meio de sentimento e imagem" ${ }^{30}$. De tal modo, Marco Moraes realizou uma leitura de $A$ Cachorra que conseguiu destacar a complexidade dos elementos internos do poema, assim como tecer algumas intertextualidades fundamentais da "dor de Menelau", que não se restringiam a algum sentimento individual do autor.

Em suma, sempre a "dor de Menelau" circulou como um complemento ao poema "A Cachorra". De qualquer forma, os sentidos desses complementos variaram com os contextos. As leituras elaboradas por poetas amigos de Prudente foram
27. BANDEIRA, Manuel.

"Poetas bissextos". In: Antologia

dos poetas brasileiros bissextos. 1946, p. 6.

28. Ibidem, p. 9.

29. MORAES, Marco Antonio de. "Sobre a dor de Menelau". Manuscrítica, 2012, p. 147.

30. Ibidem, p. 151. 
31. Cf. DERRIDA, Jacques. Gramatologia, 1973.

32. Cf. MICELI, Sergio.

Intelectuais e classe dirigente no Brasil (1920-1945), 1979. excessivamente próximas da pessoa do escritor, ao passo que Marcos Antonio de Moraes procurou estabelecer um esforço contrário, demonstrando como a dor de Menelau dos principais poemas de Prudente de Moraes, neto, poderia ser encontrada dentro da própria tradição poética e não em sua biografia ou em uma poética sentimentalista. É possível, ainda assim, sustentar outra leitura da poesia de Prudente e dessa "dor de Menelau", especialmente em sua obra mais conhecida, não necessariamente por sua vida íntima e tampouco por uma leitura adstrita aos elementos estéticos do poema, mas para destacar sua dimensão ética. Não se trata de um desmerecimento das leituras prévias. Muito pelo contrário, é possível ampliar a abrangência da “dor de Menelau" para outros âmbitos de discussão, especialmente para evidenciar a poesia de Prudente enquanto um gesto de inoperância que se manifestou como uma contraface de uma estetização da política, como na nacionalidade institucionalizada fomentada pelo Estado Novo, mas não apenas nela.

O poema "A Cachorra" quase sempre foi acompanhado de alguma menção marginal sobre a "dor de Menelau", como se carecesse de alguma glosa ou nota de censura. A partir das investigações de Derrida ${ }^{31}$, de que o caráter de complemento dos textos é sintomático do próprio poder desestabilizador da escrita, cuja iteração tende apenas a reinscrever o próprio perigo, pode-se considerar que a vinculação constante entre «A Cachorra» e a «dor de Menelau» diz respeito à própria força do poema quando tornado público. Em outras palavras, o fato desse complemento ter sido sempre mencionado em correspondências, antologias ou artigos acadêmicos apenas reforça o quanto o poema de Pedro Dantas gerou inquietude, sendo, por isso, compreensíveis suas complementações cômicas sobre as dores de amor. Embora se busque um requestionamento sobre o contexto de disseminação de «A Cachorra», não se trata, neste caso, de uma crítica sociológica. De certa maneira, os trabalhos de Sergio Miceli, especialmente em sua obra Intelectuais e classe dirigente no Brasil, trouxeram muitos subsídios no sentido de buscar esclarecer o lugar de muitos escritores a partir de sua proveniência social e dos lugares que ocuparam dentro do Estado Brasileiro, entre eles o próprio Prudente ${ }^{32}$. Entretanto, a comparação entre a ensaística e a poesia de Prudente demonstra justamente uma descontinuidade, um nada, que separa os textos, mas que é um convite para se buscar novos sentidos a partir de documentos que circularam sob a égide da política cultural do Estado Novo.

A disseminação de "A Cachorra", que veio acompanhada da "dor de Menelau", não por acaso, se iniciou em 1938, e em meio à crise da Universidade do Distrito Federal. Ainda que sua publicação em jornal tenha se dado em 1944, o poema foi 
publicado em antologia em 1946, após o fim do Estado Novo, de sorte que o grito "Eu sou A Cachorra" e a insistência na dor de Menelau não se esgotaram após a queda de Vargas. No mais, a relação entre o poema e à dor de Menelau estabelecida por Vinícius na mídia argentina também demonstra uma abrangência que vai além do biografismo ou de uma referencialidade com a condição dos intelectuais públicos no Brasil.

\section{Da formação do povo, ao povo que falta}

Mais do que uma alegoria de alguma situação biográfica do autor ou do que seria uma estrutura de sentimento de decepção por parte de intelectuais próximos ao Estado, percebe-se uma expressão paródica em relação à poesia trovadoresca e às próprias origens da língua portuguesa. Essa parodização não implica considerar que o fechamento de uma universidade e a prisão de intelectuais sob um Estado autoritário não fosse uma situação séria. Ao contrário, a paródia profana lugares canônicos para ocultar um objeto insuportável. Portanto, a remissão à tradição trovadoresca para posteriormente jogar com ela, destacando o que mais possuía de coloquial, condiz com aquilo que Agamben entrevê como próprio do paródico: "confundir e tornar duramente indiscernível o umbral que separa o sagrado e o profano, o amor e a sexualidade, o sublime e o ínfimo" 33 . Por tais razões, tanto a dor de Menelau pessoal, argumentada pelos amigos de Prudente, quanto a coita da tradição portuguesa tornam-se pertinentes enquanto gestos de uma dimensão política, que têm na linguagem seu meio de causar inoperância.

Essa busca pelo baixo fica explicitada quase como uma poética no poema "Autocrítica", aquele que mais se aproximaria de uma poética em Pedro Dantas, no qual afirma que, após ser classicista, romântico e parnasiano, voltaria às raízes populares: "Hoje, entretanto, meu verso quero / do sentimento de toda a gente, / fácil, sem arte, rude, fatal / de frases feitas, como os de Homero, / e com a força secreta e ardente / dos grandes sambas de carnaval" 34 . O processo de composição a partir das "raízes", a princípio, não seria estranho a alguém que preconizava a busca pelos momentos de formação da literatura brasileira, ressaltando especialmente aquilo que possuiria de original, a despeito de juízos de valor. Porém, diferentemente dos argumentos historiográficos de seus ensaios, a poesia de Pedro Dantas manifesta o que há de mais violento nas reverberações da tradição. Portanto, mais do que ressaltar remissões à poesia
33. AGAMBEN, Giogio.

Profanações, 2007, p. 42.

34. DANTAS, Pedro. "Autocrítica". In: MASSI, Augusto. Militante Bissexto, 2004, p. 387. 
35. DANTAS, Pedro. "Canto do Pedestre”. Revista Acadêmica, mai. 1941.

36. Idem. "A cachorra". In: Antologia dos poetas brasileiros bissextos, 1946, p. 167-168. galego-portuguesa ou à linguagem bíblica, seus poemas embaralham as cartas sobre uma mesa para apostar na singularidade de cada nova jogada, como em um lance de dados, não apenas para conceituar aquilo como a nação brasileira chegou a ser o que é, mas para abrir jogos acerca daquilo que o povo, em seus múltiplos sentidos, poderia vir a ser.

O falar popular, como se pode ver, não vem destituído de crueldade. Enquanto os ensaios de nacionalidade de Pedro Dantas estabelecem uma seleção dos momentos decisivos cabíveis para uma literatura de ideias estável ou mesmo para um povo enquanto organismo sadio, a poesia lida com a justaposição desenfreada e anárquica de elementos que colocam a regra sob suspeição. O modernista de antes, que escrevia contos sobre máquinas e parafraseava Blaise Cendrars na década de vinte, na década de quarenta trata do trânsito enquanto parte da "vida besta" em um poema construído com ritmo e figuras de som tradicionais. Na última estrofe do "Canto do Pedestre", os automóveis são personificados em meio à paródia de cantiga de amor. "Automóvel, automóvel, / Não me mates, por favor, / Deixa-me chegar à calçada / Onde espera a minha amada, / Não me mates, automóvel, / Que eu vou ver o meu amor"35.

A prosopopeia domina um dos momentos de metamorfose de "A Cachorra", em uma passagem na qual se narra um sufocamento que se relaciona à figura de um polvo, surgindo um desejo de aproximação com a morte que, no entanto, nunca é alcançado. "Veio buscar-me de novo: / Angina-pectoris, polvo. / Meu coração sufocou / E tais surras de chicote / Me deu, que a cada lambada / Minh'alma mortificada / Minh'alma perto da morte / Só a morte desejou» ${ }^{36}$. Sendo assim, em "A Cachorra", as regras habituais da vida são sobrepujadas por forças muito mais violentas que, em um plano de linguagem, podem ser transpostas por uma aceleração do ritmo causada pela iteração de rimas repetitivas ou no exagero de aliterações (v.g. me deu, que a cada lambada / minh'alma mortificada), o que produz uma sensação de sufocamento, angina-pectoris.

Ao narrar a surra infligida contra si, aquele que fala sem reagir apenas se movimenta pelas investidas da criatura, como se não possuísse vida. Mas, por outro lado, não pode morrer. Inclusive, em diversos momentos, sua morte é impedida e a tortura postergada: "insuflou-me nova vida", "veio buscar-me de novo". No entanto, a morte, única solução vislumbrada pelo eu-lírico, não consiste na grande ameaça de "A Cachorra". A monstruosidade é aquilo que se opõe à vida. E, na mesma medida em que ela própria se manifesta em metamorfoses sem ordem, também é responsável pela desfiguração do narrador. A monstruosidade, enfim, é um resultado inoperante da vida sobre si mesma: um desafio à ordenação convencional, regrada e frutífera dos viventes. 
Georges Canguilhem, em uma palestra em Bruxelas em 9 de fevereiro de $1962^{37}$, estabeleceu uma diferença entre a monstruosidade, capacidade de modificação desregrada da vida, mas ainda assim potência, do monstro propriamente dito, que, na modernidade, deixa de ser prodígio para se tornar normatizado por livros de doenças, síndromes, etc. Sua análise partiu do pressuposto de que "a monstruosidade é a ameaça acidental e condicional do inacabamento ou da distorção na formação da forma, é a limitação pelo interior, é a negação do vivente pelo não viável" 38 . A monstruosidade, além do mais, não se restringe ao campo da biologia. Paul de Man, nesse sentido, demonstrou como já em John Locke, era perceptível a inseparabilidade entre os tropos da língua e a filosofia, mais especificamente em seu Ensaio acerca do entendimento humano. Esse texto, que fundou as bases da "purificação" da língua da futura filosofia analítica perante as inconsistências da retórica, somente o fez a partir de uma série de artifícios, por sua vez, muito retóricos, como a monstruosidade, a doença, etc. Em outras palavras, nenhum pensamento, por mais racional que se queira, nunca se livra da retórica, dos tropos ou das metáforas, porque ele necessariamente possui algo de metafórico, desde a etimologia das palavras até a posição que assume perante seus contrários ${ }^{39}$.

A última estrofe do poema, que segue imediatamente a identificação de "A Cachorra", rompe com a continuidade métrica e rítmica, além de abdicar do embaralhamento de tempos e tradições como principal mecanismo de força. Ao contrário, destaca-se uma liberdade não apenas nos versos livres, mas também na quase completa abolição das rimas, capazes de trazer um ponto de vista diverso sobre as figurações de tortura. " $\mathrm{E}$ enquanto ela me mastigava os últimos restos de memória / senti que da sua boca nasciam rosas / E vi que o céu se rasgava para maravilhosa aparição" "40. A condição física do torturado não muda. Em vez disso, até sua integridade psíquica desaparece, o que, em contrapartida, foi a base para um aprendizado que não coincide com uma consciência, mas com uma nova lida com os afetos violentos tecidos na narrativa. Quando Paul de Man afirma que os tropos de linguagem, como as metáforas, não são privilégio das artes, isso também implica em se poder dizer que tropos podem suscitar saberes em diferentes linguagens, inclusive na poesia ${ }^{41}$. Pode-se entender, por isso, que a epifania da última estrofe de "A Cachorra" tem um sentido metalinguístico que não consiste em uma figuração restrita ao eu-lírico e que também não fala para algo exterior ao poema, senão que significa em conjunto com outras textualidades. Apenas há de se fazer uma ressalva de que, enquanto um conhecimento (epistème) preservaria uma relação de distância entre sujeito e objeto, a reação aos afetos consiste simplesmente em um aprendizado (gnósis) que somente se torna possível no limiar de uma dessubjetivação e nos desvios da língua.
37. A palestra foi posteriormente publicada no número $40 \mathrm{da}$ revista Diogène.

38. CANGUILHEM, Georges. La connaissance de la vie, 2009, p. 221.

39. Cf. DE MAN, Paul. "The epistemology of metaphor", 1981, p. 11-28.

40. DANTAS, Pedro. "A cachorra", 1946, p. 167-168.

41. "All philosophy is condemned, to the extent that it is dependent upon figuration, to be literary and, as the depository of this very problem, all literature is to some extent philosophical". DE MAN, Paul. "The Epistemology of Metaphor", 1981, p. 28. 
42. Jean-Luc Nancy estabelece a escritura como um corte na sociedade para a inscrição de uma comunidade pela própria inoperância, em que uma singularidade destoante reverbera com os elementos com os quais se relaciona, estabelecendo, portanto, uma relação política na imanência. "'Politique' voudrait dire une communauté s'ordonnant au desoeuvrement de sa communication ou destinée a ce desoeuvrement'. NANCY, Jean-Luc. La Communauté désouvrée, 1999 , p. 100.

43. Cf. BORGES, Jorge Luis. "A metáfora", 2000, p. 40.

44. DELEUZE, Gilles. Crítica e clinica, 2011, p. 14.
A dissolução daquele que fala para se tornar outra coisa remete a uma estética de si que, ao mesmo tempo, confunde-se com uma atitude ética e, portanto, com relevância para a vida em geral, inclusive a vida pública. Diferentemente de se organizar uma literatura de ideias, em que literatura seria o conjunto de textos para formar uma unidade ideal, o literário na poesia e na ensaística de Dantas rompe com pretensões institucionalizadoras da política cultural do Estado Novo para inscrever relações comunitárias efêmeras e inoperantes ${ }^{42}$, como na decepção comum da "dor de Menelau" ou em cada embaralhamento das "cartas na mesa". A poesia de Pedro Dantas, como se pôde observar a partir das análises de "A Cachorra", reabre tropos da linguagem que estavam latentes, transformando catacreses em metáforas novamente, como na pretenciosa "dor de Menelau", na expressão coloquial a "cachorra" ou nas, nem tão sinceras, "Cartas na Mesa". A cada novo momento em que foram disseminadas, essas expressões deixaram de ser metáforas mortas para se tornarem vivas, retomando-se o paralelo evocado por Borges, que inclusive afirmava que as metáforas são melhor aceitas que argumentos: "quando algo é simplesmente dito ou melhor ainda — insinuado, há uma espécie de hospitalidade em nossa imaginação" ${ }^{43}$.

Em paralelo à ensaística de formação nacional que era ensaiada na revista Cultura Política, a qual seria a base para o nacional-popular das décadas seguintes, por exemplo, em pensadores do ISEB ou da revista Civilização Brasileira, tanto o tradicional quanto o popular, de Homero aos Sambas de Carnaval, aparecem como monstruosidades nas figurações de Pedro Dantas. $\mathrm{E}$, desse modo, pode-se pensar um povo sempre em devir, que, logo, não se confunde com uma busca por origem ou alguma essência por parte de Prudente de Moraes, neto. Nesse sentido, é possível relembrar a conceituação de Deleuze de que "a saúde, como literatura, como escrita, consiste em inventar um povo que falta. Compete à função fabuladora inventar um povo" 44 . A partir daí, pode-se pensar também que o mal-estar alastrado entre os que estavam simultaneamente protegidos e ameaçados pela política cultural do Estado Novo não determinou a disseminação tragicômica da poesia de Pedro Dantas, muito embora tenha interagido com ela, especialmente ao reiterar essas palavras em mídias públicas: "Eu sou a Cachorra".

\section{Considerações Finais}

Prudente de Moraes, neto, enquanto homme de lettres, projetou-se veladamente na discussão pública brasileira ao longo do século XX. De um lado, seus estudos acadêmicos e ensaísticos 
sugerem uma adesão ao Estado Novo. A ensaística de Prudente em órgãos culturais do Estado Novo sustentou uma formação nacional espontânea que logo seria a base para uma busca pelo nacional no popular. Se essa iniciativa se assemelha a de muitos outros intelectuais e artistas da mesma época, muitos deles reunidos na revista Cultura Política, tal ecletismo também poderia ser entendido como uma conformação intelectual que dispensava uma clara posição ideológica. Ángel Rama, ao analisar o caso brasileiro, mas estendendo-o a outras experiências pós-revolucionárias da América Latina, afirmou que: "la esfera nacionalista era mucho más accesible que la sabiduría universal procurada por los 'ilustrados' de la modernización, pues la proveía simplemente el nacimiento y las tradiciones formativas, careciendo además de una orientación ideológica precisa"45. Ainda assim, essa dispensa ideológica é verdadeira apenas até o momento em que não são observadas as descontinuidades desses autores. Nesse sentido, a leitura aqui proposta buscou salientar a dose de "nada" em metáforas como a das "cartas na mesa", "dor de Menelau" ou da "Cachorra" como aquilo que sempre se reescreve na ensaística e na poesia de Pedro Dantas e que, quando se repetem em outros contextos, são pura diferença.

Seria igualmente forçoso pensar que os textos vanguardistas de Prudente na década de 20, como "Os Mortais de Nero" ou sua crítica na revista Estética, tenham perdido sua força contestadora se comparados com os de Pedro Dantas durante o Estado Novo por seu apego à tradição, aparelhamento com o Estado e seu menor experimentalismo. Hal Foster ${ }^{46}$ entendeu que as vanguardas não se dão em um momento único e definitivo, senão que seus efeitos e desdobramentos são frutos de suas releituras e refigurações sucessivas. De modo semelhante, poemas como "A Cachorra" ou "Cantiga de Mestria", de Pedro Dantas, perfazem uma lida anacrônica e inoperante com a tradição ou com a linearidade temporal de seus próprios conceitos historiográficos presentes na coluna "Literatura de Ideias". Portanto, as políticas culturais do Estado Novo não foram suficientes para determinar a politicidade da obra de Prudente de Moraes, neto, e de Pedro Dantas. Certo é que, desde a Era Vargas, mas não apenas nela, o grito "Eu sou a Cachorra" pode ser ecoado novamente para condensar diversas dores de Menelau em face das intempéries das políticas culturais do Estado Brasileiro.

Em seu estudo Literatura em Revista, Raul Antelo verificou, em contraste com as análises sociológicas de $\mathrm{Miceli}^{47}$, como o próprio varguismo e sua política cultural não estavam poupados de contradições, de modo que prevaleceram tensões entre a classe artística e o Estado, mais propriamente do que cooptações pacíficas: "Vencedores, enquanto beneficiários do processo de modernização, encontram-se vencidos por um sistema
45. RAMA, Ángel. La ciudad letrada, 2004, p. 163.

46. Cf. FOSTER, Hal. O retorno do real, 2017.

47. MICELI, Sergio. Intelectuais e classe dirigente no Brasil (19201945), 1979. 
48. ANTELO, Raul. Literatura em revista, 1984, p. 6. rígido em que a modernidade é mais aparente que real"48. Essas contradições são bastante evidentes na obra de Prudente de Moraes, neto. A partir dos anos 40, sua coluna "Literatura de Ideias" discute cultura popular no intuito de descobrir uma formação nacional e um homem novo, algo que destoa de sua própria poesia que, pelo menos desde 1938, retoma a tradição e o popular de modo não organicista. Nesse gesto, surge uma monstruosidade da própria linguagem e um aprendizado a partir de um choque violento de diferentes temporalidades e afetos. A poesia de Pedro Dantas traz à tona um nada que carece de significado, mas que suscita a significação, podendo ser lida como a parte maldita de suas próprias teorizações ensaísticas acerca de uma formação espontânea, porém linear, da nacionalidade brasileira.

\section{Referências}

AGAMBEN, Giorgio. Profanações. Tradução de Selvino José Assmann. São Paulo: Boitempo, 2007.

ANTELO, Raul. Literatura em revista. São Paulo: Ática, 1984.

BANDEIRA, Manuel (Org.). Antologia dos poetas brasileiros bissextos. Manuel Bandeira (Org.) Rio de Janeiro: Zélio Valverde, 1946. ."Poetas bissextos". In: - Antologia dos poetas

brasileiros bissextos. Manuel Bandeira (Org.) Rio de Janeiro: Zélio Valverde, 1946. . "Poetas Bissextos". A Manhã. p. 117-125, 3 set. 1944.

BARBOSA, Ana Claudia Bandeira. Perfil de Prudente de Moraes, neto. Tese (Mestrado em Teoria Literária e Literatura Comparada) - Faculdade de Ciências e Letras da UNESP, Assis, 2002.

BARTHES, Roland. Inéditos v. 4 - política. Tradução de Ivone C. Benedetti. São Paulo: Martins Fontes, 2005.

BENJAMIN, Walter. "Experiência e pobreza". In: Magia e Técnica, arte e politica. Ensaios sobre literatura e história da cultura. Tradução Sergio Paulo Rouanet. São Paulo: Brasiliense, 1994.

BORGES, Jorge Luis. "A metáfora”. In: Esse oficio do verso. Tradução de José Marcos Macedo. São Paulo: Companhia das Letras, 2000, p. 29-49. 
CANDIDO, Antonio. Formação da Literatura Brasileira: momentos decisivos. São Paulo: Martins, 1959.

CANGUILHEM, Georges. La connaissance de la vie. Paris: Vrin, 2009.

DANTAS, Pedro. "A Cachorra". In: BANDEIRA, Manuel

(Org.). Antologia de poetas brasileiros bissextos contemporâneos. Rio de Janeiro: Zélio Valverde, 1946, p. 167-168.

"Cantiga de Mestria". Letras e Artes. Rio de Janeiro,

n. 36, p. 8, 30 mar. 1947.

"Canto do pedestre". Revista Acadêmica. Rio de Janeiro, n. 54, mai. 1941.

. "Literatura de ideias I". Cultura Politica Rio de Janeiro, $\mathrm{n}^{\circ} 1$, p. 257-259, 1941.

DELEUZE, Gilles; GUATTARI, Felix. Mil Platôs: capitalismo e esquizofrenia, v. 4. Tradução de Suely Rolnik. São Paulo: 34, 2000.

DE MAN, Paul. "The epistemology of metaphor". In:

SACKS, Sheldon. On metaphor. Chicago: The University of

Chicago Press, 1981, p. 11-28.

DERRIDA, Jacques. Gramatologia. Tradução de Miriam

Schnaiderman e Renato Janini Ribeiro. São Paulo: Perspectiva, 1973.

FACIOLI, Valentim. "Modernismo, vanguardas e surrealismo no Brasil". PONGE, Robert (Org.). Surrealismo e novo mundo. Porto Alegre: Editora da UFRGS, 1999, p. 298.

FÁVERO, Maria de Lourdes. "Anísio Teixeira e a Universidade do Distrito Federal". Revista Brasileira de História da Educação. Maringá, v.8, n. 2, p. 161-180, 2008.

FOSTER, Hal. O retorno do real: a vanguarda no final do século XX. Tradução de Célia Euvaldo. São Paulo: Ubu Editora, 2017.

FOUCAULT, Michel. A coragem da verdade. Tradução de Eduardo Brandão. São Paulo: Martins Fontes, 2014.

MASSI, Augusto. Militante Bissexto: o crítico Prudente de Moares, neto. Tese. (Doutorado em Letras) - Departamento de Letras Clássicas e Vernáculas da Faculdade de Filosofia, Letras e Ciências Humanas da Universidade de São Paulo, São Paulo, 2004.

MICELI, Sergio. Intelectuais e classe dirigente no Brasil (1920-1945).

São Paulo: Difel, 1979. 
MORAES, Marcos Antonio de. "Sobre a dor de Menelau". Manuscrítica. Campinas, no 8, p. 133-152, 2012.

MORAES, NETO, Prudente de. "Sobre a sinceridade". Estética. Rio de Janeiro, n. 2, p. 159-164, jan-mar. 1925.

NANCY, Jean-Luc. La Communauté désouvrée. Paris:

Flammarion, 1999.

RAMA, Ángel. La ciudad letrada. Santiago: Cajamar, 2004. 